\title{
The breeding system of Villarsia exaltata (Menyanthaceae), a distylous species
}

\author{
Robert Ornduff
}

\begin{abstract}
Ornduff Robert, Department of Integrative Biology, University of California, Berkeley, California 94720-3140 USA) 1996. The breeding system of Villarsia exaltata (Menyanthaceae), a distylous species. Telopea 6(4): 805-811. Ten of the 15 species of the predominantly Australian genus Villarsia have distylous flowers. Eight of these are diploid or predominantly so. In six species the incompatibility relationships within and between the two morphs resemble the expected type, but the distylous breeding systems of four species deviate from that conventionally associated with distyly. This paper reports on the breeding system of the widespread eastern Australian Villarsia exaltata, which has distylous flowers, striking dimorphisms in style length and stigma morphology of the two floral types, high pollen stainability, but not consistent intermorph size differences in the pollen grains. Unlike the other distylous Australian species, $V$. exaltata is hexaploid. Intermorph pollinations of pin plants (those with long-styled flowers) produced 5.6 times more seeds than intramorph pollinations; intermorph pollinations of thrum plants (those with short-styled flowers) produced 33.4 times more seeds than intramorph pollinations. Thus an incompatibility system is associated with distyly in this species; the system appears to be stronger in thrum plants than in pin plants. Pollinations utilizing different pairs of parent plants often differed in mean seed-sets following a given class of pollination. Some intramorph pollinations produced unexpectedly high seed-sets that were equal or nearly equal to those produced by intermorph pollinations of the same seed parent. The breeding system of $V$. exaltata is not considered to represent a condition ancestral to the derivative breeding systems associated with distyly elsewhere in the genus, but it demonstrates the kind of intrapopulation variability that is necessary before natural selection can lead to the development of these derivative systems. Little is known of the population biology or the functioning of distyly in natural populations of $V$. exaltata, features that would reward study by botanists resident within the range of this species.
\end{abstract}

\section{Introduction}

Distyly is a genetic polymorphism conventionally defined by reciprocity in positions of stigmas and anthers of the flowers of the two morphs (Barrett 1992). Long-styled flowers are termed pin flowers, and short-styled flowers are termed thrum flowers (Darwin 1877). Distyly has been reported in over two dozen angiosperm families (Lloyd and Webb 1992). Commonly it is associated with strong intramorph incompatibility and strong intermorph compatibility and by differences in size and other features of pollen grains and stigmas of the two morphs. There are other less widespread features associated with distyly in various species (Lloyd and Webb 1992). Ten of the 15 species of the predominantly Australian genus Villarsia (Menyanthaceae) are distylous (eight of these are diploid or predominently so) and four species are not heterostylous (Ornduff 1982, 1986, 1988a, b, 1992); the floral condition of $V$. cambodiana Hance is unknown (Ornduff 1994). Four Western Australian species of Villarsia exhibit more or less conventional distyly, with the expected intramorph incompatibility and intermorph compatibility, pollen size differences, and reciprocal positions of anthers and stigmas (Ornduff 1982, 1988a,b, 1992, unpublished; see following discussion). In two distylous Western Australian species both morphs are self-incompatible, pin plants are crossincompatible, and thrum plants show high levels of cross-compatibility (Ornduff 1988b, in press; see following discussion). In two other distylous Western Australian species 
both morphs are highly self-compatible as well as cross-compatible, but thrum plants exhibit high levels of autogamy (Ornduff unpublished; see following discussion). Thus, in Australian species of Villarsia, at least three different breeding systems are associated with distyly: a more or less conventional one as well as two breeding systems combining unexpected mixtures of incompatibility and compatibility relationships of the two morphs. Although deviations from conventional distyly are known in other families, the combinations of compatibility and incompatibility associated with distyly in four species of Villarsia are unknown outside the genus (Ganders 1979a; Casper 1992; Dulberger 1992; Lloyd and Webb 1992). The nature of the breeding system in a Villarsia species thus cannot be inferred merely by the presence of distylous flowers.

This paper describes the breeding system of Villarsia exaltata (Solander ex Sims) G. Don, a robust, perennial, aquatic or wetland hexaploid species ranging from coastal southern Queensland (the Gympie region) through coastal New South Wales to central coastal Victoria (Cranbourne), with outlying populations in northeastern Tasmania (Aston 1969). The species has distylous flowers (illustrated by Aston, 1969, Fig. 27). Stigmas of pin flowers are exserted well beyond the mouth of the corolla and stigmas of thrum flowers are positioned at or below the mouth of the corolla (Aston 1969, Fig. 27). Anthers of each floral form occupy positions approximately equivalent to positions occupied by the stigmas of the other form. Pin stigmas are lanceolate and densely covered with papillae on the inner face and all but the median portion of the outer face, whereas thrum stigmas are more or less deltoid with papillae uniformly covering both the outer and inner faces (Aston 1969, Fig. 27; Dulberger and Ornduff unpublished.).

Villarsia exaltata is the only one of the three eastern Australian Villarsia species that has distylous flowers; the flowers of $V$. reniformis $\mathrm{R}$. Br. and V. umbricola Aston are not heterostylous. These three eastern Australian species are hexaploid with $\mathrm{n}=27$ ( $V$. exaltata, V. umbricola) or hexaploid with rare tetraploid populations ( $V$. reniformis; Ornduff 1974). The distylous Western Australian Villarsia species are diploid, although tetraploid races occur in one of them (Ornduff 1974; Ornduff and Chuang 1988). This paper presents the results of an artificial pollination program carried out on cultivated plants of $V$. exaltata, a program designed to identify the presence and nature of the incompatibility system, if any, that is associated with the pronounced floral dimorphism of this species.

\section{Materials and methods}

Seeds of Villarsia exaltata were obtained from a population native to the grounds of the North Coast Regional Botanical Garden at Coffs Harbour, New South Wales, in the mid-1980s. Plants were grown to maturity in the greenhouses of the Department of Botany, University of California at Berkeley and upon flowering were assigned identifying codes indicating the morph and a plant number. A second collection of seeds obtained by J. A. West at Wilsons Promontory, Victoria, in 1991 contained a mixture of seeds of $V$. exaltata and $V$. reniformis that were growing sympatrically. This collection produced only a few thrum plants of $V$. exaltata, plants of $V$. reniformis, and several hybrids between the two species. In order to eliminate the possibility of dioecy in $V$. exaltata, pollen viabilities were estimated for five pin and four thrum plants of the Coffs Harbour progeny by mounting pollen grains in aniline blue-lactophenol on a glass slide and scoring stained grains in a minimum sample of 100 pollen grains. Pollen size was measured using a sample of 10 pollen grains from each of three plants of the two morphs in the Coffs Harbour progeny with an ocular micrometer.

Six pin plants and four thrum plants of the Coffs Harbour progeny and four thrum plants of the Wilsons Promontory progeny were used in a pollination program 
carried out between 1986 and 1994. It included self-pollinations, intramorph xenogamous pollinations, and intermorph pollinations. Each pollination was carried out by removing a dehisced anther from the desired pollen parent with fine forceps and applying the anther to the stigma of the prospective seed parent. The pedicel of the latter flower was tagged with a string tag indicating the nature of the cross and the date. A minimum of five pollinations of each individual seed parent $\times$ pollen parent combination was attempted, but in several instances the number achieved was lower than this. In approximately a month's time, as the capsules were nearly mature, they were harvested, placed individually in labeled coin envelopes, and the seeds were counted. Mean seed production figures with standard deviations were calculated for each combination and each type of pollination.

\section{Results}

Pollen stainability and size Pollen stainabilities of five pin plants of the Coffs Harbour progeny ranged from $86 \%$ to $100 \%$ with a mean of $93.2 \%$ for the five plants. Pollen stainabilities of three thrum plants in that progeny ranged from $78 \%$ to $97 \%$ with a mean of $89.3 \%$ for the three plants. These figures suggest that the pollen of both morphs has high levels of viability. Mean pollen diameters of 38.4 \pm 1.6 ( plant L-2), $38.8 \pm 1.4$ (L-1), and $41.3 \pm 2.3(\mathrm{~L}-5) \mu \mathrm{m}$ were obtained for three pin plants; mean pollen diameters of $42.7 \pm 2.5$ (S-9), $45.4 \pm 2.1$ (S-8), and $48.6 \pm 2.7$ (S-7) $\mu \mathrm{m}$ were obtained for three thrum plants. Two pin plants sampled had smaller pollen grains than two thrum plants, but one plant of each morph had pollen grains of equal size, indicating that pollen sizes are not consistently different between the two morphs.

Seed-set in the Wilsons Promontory progeny Since only four thrum plants of the Wilsons Promontory sample were available, the results of the pollination program using these plants will be summarized and not presented in tabular form. Three of the four thrum plants were self-pollinated five times; one seed was produced from these 15 self-pollinations, with a mean of 0.07 seeds per self-pollination. All four thrum plants were pollinated by two other thrum plants, with a total of 40 intramorph xenogamous pollinations carried out. One seed was produced by each of two thrum plants after such pollinations, with a mean seed-set of 0.05 seeds per pollination. Mean seed-sets from self-pollinations and from xenogamous intramorph pollinations in this sample of thrum plants thus were equivalent.

The following results were obtained from the Coffs Harbour progeny.

Self-pollinations (Table 1) The collective mean seed-set of the six pin plants following self-pollination was 2.6 seeds per pollination and of the four thrum plants it was 1.3 seeds per pollination.

Intramorph xenogamous (= interplant) pollinations (Table 1) The six pin plants were pollinated by three or more other pin plants serving as pollen parents. The mean seed-set of these pin plants following intramorph xenogamous pollinations was 4.3 seeds per pollination. The four thrum plants were pollinated by one or more other thrum plants serving as pollen parents. The mean seed-set of these thrum plants following intramorph xenogamous pollinations was 0.1 seeds per pollination.

Intermorph pollinations (Table 1) Each of six pin plants was pollinated by all four thrum plants serving as pollen parents. The mean seed-set of pin plants following these pollinations was 21.1 seeds per pollination. Each of the four thrum plants was pollinated by all six pin plants. The mean seed-set of thrum plants following these pollinations was 16.7 seeds per pollination. 
Table 1. Mean seed production (standard deviation; sample size) following artificial self-pollinations, intramorph xenogamous pollinations, and intermorph pollinations in a cultivated progeny of Villarsia exaltata. Plant numbers are given for seed parents (vertically on the left) and for the same plants as pollen parents (horizontally on the top) of long- and short-styled plants used in the pollination program.

\section{Long (Pin)}

2

3

$11.4(3.5 ; 7) \quad 2.6(4.1 ; 9)$

$-$

$2 \quad 25.6(5.1 ; 9) \quad 3.2(3.6 ; 20)$

$0(3)$

$3 \quad 7.0(6.2 ; 3) \quad 0(3)$

Long

$4 \quad 12.9(4.4 ; 13) \quad 0(4)$

$5 \quad 15.3(7.8 ; 11) \quad 3.2(6.4 ; 5)$

$6 \quad 1.5(3.4 ; 6)$

$0(7)$

$0(14)$

$0(3)$

$O(2)$

$0(6)$

$1.2(1.6 ; 4)$

$0(3)$

$1.1(1.6 ; 15)$

$0(3)$

$0(6)$

$-$

$6.4(2.9 ; 5)$

o(3)

$3.8(3.9 ; 4)$

$0.5(1.7 \cdot 11)$

$0(10)$

$0(6)$

$7 \quad 24.8(9.3 ; 7)$

$29.8(12.1 ; 7)$

$33.3(5.5 ; 6)$

$36.5(6.9 ; 6)$

$35.2(7.9 ; 5)$

$42.8(6.0 ; 5)$

$9.6(6.2 ; 10)$

$21.8(10.3 ; 9)$

$23.4(9.2 ; 9)$

$23.0(5.8 ; 5)$

15.5(2.6;6)

$14.5(10.3 ; 6)$

$3.7(1.7 ; 6)$

3.6(3.1;10)

5.6(3.0;5)

$4.8(2.4 ; 6)$
Short (Thrum)

8

9

10

$\begin{array}{llll}17.1(7.6 ; 7) & 22.3(2.6 ; 3) & 23.5(3.6 ; 4) & 21.2(4.6 ; 6) \\ 22.5(3.7 ; 6) & 27.4(12.5 ; 10) & 30.7(4.2 ; 6) & 21.5(3.8 ; 6) \\ 29.6(3.9 ; 5) & 28.2(5.7 ; 6) & 33.7(6.6 ; 6) & 27.8(4.8 ; 6) \\ 13.0(4.8 ; 6) & 12.0(3.7 ; 4) & 15.4(6.6 ; 11) & 6.5(3.2 ; 6) \\ 9.4(8.9 ; 7) & 11.2(11.0 ; 11) & 18.1(10.2 ; 6) & 13.5(5.4 ; 6) \\ 29.3(5.7 ; 6) & 28.8(13.8 ; 6) & 27.8(14.5 ; 6) & 28.7(12.0 ; 6)\end{array}$

$6.2(13.8 ; 6) \quad-$

o(6)

-

o(5)

$-$

$0(10)$

$0(10)$

$0(10)$

o(5)

$0.6(1.0 ; 7)$

$0(6)$

O(6)

$0.6(1.6 ; 14)$ 


\section{Discussion}

Villarsia exaltata possesses an incompatibility system linked to its floral dimorphism. The strength of this incompatibility system can be expressed by comparing mean seed-sets following intramorph pollinations with mean seed-sets obtained from intermorph pollinations. In the Coffs Harbour progeny, the mean seed-set of thrum plants was 0.5 seeds per intramorph pollination and 16.7 seeds per intermorph pollination. The mean seed-set of thrum plants after intermorph pollinations thus was 33.4 times greater than that after intramorph pollinations. The mean seed-set of pin plants was 3.8 seeds per intramorph pollination and 21.1 seeds per intermorph pollination. The mean seed-set of pin plants after intermorph pollinations thus was 5.6 times greater than that after intramorph pollinations. These figures suggest that the strength of incompatibility differs between the two morphs, with that of thrum plants about six times greater than that of pin plants. It is possible, however, that this may instead reflect a difference in mean ovule numbers of flowers of the two morphs, a feature that unfortunately was not measured. Only thrum plants were present in the Wilsons Promontory progeny; these also produced low seed-sets after self- and intramorph pollinations. Pollen stainabilities of both morphs in the Coffs Harbour progeny were high, and pollen sizes of the two morphs were not consistently different.

The preceding figures offer a summary of the strength of the incompatibility system at the population level in Villarsia exaltata, but they do not convey the level of variability among plants in the functioning of this system. In the Coffs Harbour progeny, mean seed-sets of individual thrum plants after self-pollinations ranged from 0 to 0.37 times (in S-7) that following intermorph pollinations. Mean seed-sets of individual pin plants after self-pollinations ranged from 0 to 0.5 times (in L-1) that following intermorph pollinations. Mean seed-sets of thrum plants after xenogamous intramorph pollinations were uniformly very low, but in pin plants they ranged from 0 to 1.2 times (in L-2) that following intermorph pollinations of the same plants. One pin plant (L-2) produced a mean of 25.6 seeds per pollination with L- 1 as the pollen parent, and a mean seedset of 25.8 seeds following all pollinations with thrum plants. One intramorph pollination combination of this pin plant thus produced a mean seed-set equal to that of the same plant following intermorph pollinations. Used as a pollen parent in pin plant $x$ pin plant pollinations, $L-1$ produced seed-sets in three pin plants (L-2, L-4, L-5) that exceeded the mean seed-sets of these same pins in some intermorph pollinations. The strength of self-incompatibility and of intramorph crossincompatibility in pin plants of $V$. exaltata clearly varies depending on the pair of parent plants used. The explanation for this variability is unclear, since on physiological and genetic bases the seed-set from pin plant $x$ pin plant pollinations should be equivalent to that from self-pollinations of pin plants.

Mean seed-sets of individual pin plants following all intermorph pollinations of them ranged from 14.4 and 12.2 in L-4 and L-5, respectively, to 28.6 and 29.8 in L-6 and L-3, respectively, thus differing by factors of 1.9-2.4 for the same category of pollination in the progeny. Mean seed-sets of individual thrum plants following all intermorph pollinations of them ranged from 3.8 in S-10 to 30.5 in S-7, thus differing by a factor of 8.0 . While L-4, L-5, and S-10 functioned poorly as maternal parents, they functioned well as male parents in intermorph pollinations. The effectiveness of individual plants in their male and female functions thus varied depending on the combinations of parental plants involved in pollinations.

Since the pioneering studies of Darwin (1877) it has been usual to report seed-set data obtained from pollination programs of heterostylous species as pooled data, usually collected from a single flowering season (e.g. Ganders 1975; Philipp and Schou 1981; Ornduff 1982, 1988b; Goldblatt and Bernhardt 1990). This practice 
obscures intrapopulation variability that may occur in some heterostylous species, or variation in breeding systems that occurs over a period of years (e.g. Ornduff 1976, 1980). Other more detailed methods of reporting seed-set data have revealed interesting intrapopulation differences in breeding systems (e.g. Ganders 1979a,b; Nicholls 1985; Barrett and Anderson 1985; Glover and Barrett 1986) as well as interpopulation differences (e.g. Weller 1979, Barrett 1985). Villarsia exaltata shows plant-to-plant differences in fecundity after various pollination combinations in both morphs and some pins show unexpectedly high levels of seed-set following what should be incompatible crosses. In these respects, the breeding system of this species parallels that of the Western Australian V. lasiosperma F. Muell. (Ornduff 1992), which is considered by Aston (1969) to be a close relative of $V$. exaltata.

As mentioned above, 10 of the 15 species of Villarsia have distylous flowers and four have flowers that are not heterostylous. The breeding system associated with distyly in the South African V. capensis (Houtt.) Merrill (Ornduff unpublished), the Western Australian V. capitata Nees (Ornduff 1982) , V. congestiflora F. Muell. (Ornduff 1988a), and $V$. latifolia Benth. (Ornduff unpublished) appears to be more or less conventional, i. e., with generally strong intramorph incompatibility and high levels of intermorph compatibility. The Western Australian $V$. calthifolia F. Muell. and V. violifolia F. Muell. have distylous flowers but with high levels of intra- and intermorph compatibility of both morphs (Ornduff unpublished). The distylous Western Australian $V$. marchantii Ornduff (Ornduff unpublished) and $V$. parnassiifolia (Labill.) $\mathrm{R}$. Br. (Ornduff 1986, in press) have pins with strong intramorph incompatibility, but thrum $x$ thrum pollinations are relatively fecund. The Western Australian V. albiflora F. Muell. (Ornduff 1986, in press) and $V$. submersa Aston (Ornduff unpublished) have flowers that are not heterostylous, exhibit strong self-incompatibility, and high interplant compatibility. The eastern Australian $V$. reniformis $\mathrm{R}$. Br. has flowers that are not heterostylous, but it is uncertain whether the species is uniformly self-incompatible, self-compatible, or exhibits both conditions (Ornduff unpublished). The southeastern Australian $V$. umbricola Aston likewise has flowers that are not heterostylous, but these are highly self-compatible, show high levels of autogamy, and are probably recombinant homostyles (Ornduff unpublished).

The small genus Villarsia exhibits a diversity of breeding systems, most of which seem to be derived from an ancestral, conventional distyly. The significance of intraspecific variation in distylous breeding systems in this genus is unknown, but the unexpected features in breeding systems that characterize $V$. marchantii and $V$. parnassiifolia could have developed only from an ancestral distylous breeding system in which conventional morphological distyly is associated with relaxed incompatibility in one or both morphs. The breeding system of $V$. exaltata does not represent a postulated ancestral condition of any derivative breeding system known in the genus. However, the plant-to-plant variation in breeding system found within the single population studied of this species is a prerequisite condition to the breakdown of distyly that has occurred elsewhere in the genus. Much remains to be discovered about the breeding system of $V$. exaltata: for example, we know nothing of morph ratios of pin and thrum plants in the field, its pollination biology, fecundity of the two morphs under field conditions, or interpopulation differences in breeding system and the morphological expression of distyly. These merit study by botanists who are resident in the natural range of this species.

\section{Acknowledgements}

I thank the staff and volunteers of the North Coast Regional Botanical Garden at Coffs Harbour and John A. West for providing seeds of Villarsia exaltata, and Helen Aston and Robert Whelan for helpful comments on an earlier draft of this paper. 


\section{References}

Aston, H.I. (1969) The genus Villarsia (Menyanthaceae) in Australia. Muelleria 2: 3-63.

Barrett, S.C.H. (1992) Heterostylous genetic polymorphisms: model systems for evolutionary analysis. In S. C. H. Barrett, ed., Evolution and function of heterostyly (Springer-Verlag: Berlin).

Barrett, S.C.H. (1985) Floral trimorphism and monomorphism in continental and island populations of Eichhornia paniculata (Spreng.) Solms (Pontederiaceae). Biol. J. Linn. Soc. 25: 41-60.

Barrett, S.C.H., and Anderson, J.M. (1985) Variation in expression of trimorphic incompatibility in Pontederia cordata L. (Pontederiaceae). Theor. Appl. Genet. 70: 355-362.

Casper, B.B. (1992) The application of sex allocation theory in heterostylous plants. In S.C.H. Barrett (ed.), Evolution and function of heterostyly (Springer-Verlag: Berlin).

Darwin C. (1877) The different forms of flowers on plants of the same species (Murray: London).

Dulberger, R. (1992) Floral polymorphisms and their functional significance in the heterostylous syndrome. In S. C. H. Barrett (ed.), Evolution and function of heterostyly (Springer-Verlag: Berlin).

Ganders, F.R. (1975) Fecundity in distylous and self-incompatible homostylous plants of Mitchella repens (Rubiaceae) Evolution 29: 186-188.

Ganders, F.R. (1979a) The biology of heterostyly. New Zealand J. Bot. 17: 607-635.

Ganders, F.R. (1979b) Heterostyly in Erythroxylum coca (Erythroxylaceae). Biol. J. Linn. Soc. 78: 11-20.

Glover, D.E., \& Barrett, S.C.H. (1986) Variation in the breeding system of Eichhornia paniculata (Spreng.) Solms. (Pontederiaceae). Evolution 40: 1122-1131.

Goldblatt, P., \& Bernhardt, P. (1990) Pollination biology of Nivenia (Iridaceae) and the presence of heterostylous self-compatibility. Israel J. Bot. 39: 93-111.

Lloyd, D.G., \& Webb, C.J. (1992) The evolution of heterostyly. In S.C.H. Barrett (ed.), Evolution and function of heterostyly (Springer-Verlag: Berlin).

Nicholls, M.S. (1985) Pollen flow, population composition, and the adaptive significance of distyly in Linum tenuifolium L. (Linaceae). Biol. J. Linn. Soc. 25: 235-242.

Ornduff, R. (1974) Cytotaxonomic observations on Villarsia (Menyanthaceae). Austral. J. Bot. 22: 513-516.

Ornduff, R. (1976) The reproductive system of Amsinckia grandiflora, a distylous species. Systematic Bot. 1: $57-66$.

Ornduff, R. (1980) Heterostyly, population composition, and pollen flow in Hedyotis caerulea. Amer. J. Bot. 67: 95-103.

Ornduff, R. (1982) Heterostyly and incompatibility in Villarsia capitata (Menyanthaceae). Taxon 31: 495-497.

Ornduff, R. (1986) Comparative fecundity and population composition of heterostylous and nonheterostylous species of Villarsia (Menyanthaceae) in Western Australia. Amer. J. Bot. 73: 282-286.

Ornduff, R. (1988a) Distyly and incompatibility in Villarsia congestiflora (Menyanthaceae), with comparative remarks on V. capitata. Pl. Syst. Evol. 159: 81-83.

Ornduff, R. (1988b) Distyly and monomorphism in Villarsia (Menyanthaceae): some evolutionary considerations. Ann. Missouri Bot. Gard. 75: 761-767.

Ornduff, R. (1992) Intrapopulation variation in the breeding system of Villarsia lasiosperma (Menyanthaceae), a distylous species. Pl. Syst. Evol. 180: 227-233.

Ornduff, R. (1994) Villarsia cambodiana (Menyanthaceae) in southeastern Asia. Nord. J. Bot. 14: $647-648$.

Ornduff, R., and Chuang, T.I. (1988) Chromosome numbers of Western Australian species of Villarsia (Menyanthaceae). Pl. Syst. Evol. 161: 49-52.

Ornduff, R. (in press). An unusual floral monomorphism in Villarsia (Menyanthaceae) and its proposed origin from distyly. In S. D. Hopper et al. (eds), Gondwanan heritage: past, present and future of the Western Australian biota (Surrey Beatty: Chipping Norton).

Philipp, M., and Schou, O. (1981) An unusual heteromorphic incompatibility system. Distyly, selfincompatibility, pollen load and fecundity in Anchusa officinalis (Boraginaceae). New Phytol. 89: 693-703.

Weller, S.G. (1979) Variation in heterostylous reproductive systems among populations of Oxalis alpina in southeastern Arizona. Systematic Bot. 4: 57-71. 